Article

\title{
Effect of Oxygen Partial Pressure on the Phase Stability of Copper-Iron Delafossites at Elevated Temperatures
}

\author{
Thomas Stöcker ${ }^{(D)}$ and Ralf Moos* \\ Department of Functional Materials, Zentrum für Energietechnik (ZET), University of Bayreuth, \\ 95440 Bayreuth, Germany \\ * Correspondence: functional.materials@uni-bayreuth.de; Tel.: +49-921-557401
}

Received: 13 September 2018; Accepted: 28 September 2018; Published: 2 October 2018

check for updates

\begin{abstract}
Oxide-based materials are promising candidates for use in high temperature thermoelectric generators. While their thermoelectric performance is inferior to commonly used thermoelectrics, oxides are environmentally friendly and cost-effective. In this study, $\mathrm{Cu}$-based delafossites $\left(\mathrm{CuFeO}_{2}\right)$, a material class with promising thermoelectric properties at high temperatures, were investigated. This work focuses on the phase stability of $\mathrm{CuFeO}_{2}$ with respect to the temperature and the oxygen partial pressure. For this reason, classical material characterization methods, such as scanning electron microscopy, energy dispersive X-ray spectroscopy, and X-ray diffraction, were combined in order to elucidate the phase composition of delafossites at $900{ }^{\circ} \mathrm{C}$ at various oxygen partial pressures. The experimentally obtained results are supported by the theoretical calculation of the Ellingham diagram of the copper-oxygen system. In addition, hot-stage X-ray diffraction and long-term annealing tests of $\mathrm{CuFeO}_{2}$ were performed in order to obtain a holistic review of the phase stability of delafossites at high temperatures and varying oxygen partial pressure. The results support the thermoelectric measurements in previous publications and provide a process window for the use of $\mathrm{CuFeO}_{2}$ in thermoelectric generators.
\end{abstract}

Keywords: delafossite; Ellingham diagram; phase stability; high temperature thermoelectric materials; thermoelectric generator (TEG)

\section{Introduction}

In past years, huge efforts have been undertaken to cope with global warming and climate change, mainly originating of ever-growing economics and societies in industrial countries. By doing so, it is a significant challenge to recycle the waste-heat, accountable for up to $60 \%$ of all energy losses, using efficient energy converters. Thermoelectric generators (TEG) make use of the Seebeck effect to directly convert thermal into electrical energy. Various material combinations have been investigated in the last decades, especially for applications in mid-temperature ranges [1-7]. Thereby, various material combinations have been used to increase conversion efficiency, but not focusing on cost efficiency, availability, and sustainability.

Hence, oxide thermoelectrics have attracted much attention in recent years for use in thermoelectric generators [8-18]. Whereas commonly used material classes such as chalcogenides [19-29], skudderudites [30-32], and polymers [33-37] exhibit good thermoelectric performance at low- and mid-temperature ranges, oxides show their advantages at elevated temperatures above $700{ }^{\circ} \mathrm{C}$. Above all, oxide materials follow the prevailing trend to substitute costly and less abundant thermoelectrics in favor of inexpensive materials. Whereas their thermoelectric performance might be inferior to prevalently used materials, oxides exhibit a remarkable relationship between thermoelectric performance and 
cost. Thus, thermoelectric oxides make use of their inherent advantages where no high-performance thermoelectric efficiency is required, but the application of cost-effective and environmentally friendly materials are a must.

Lately, several promising groups of oxide thermoelectrics were reported to have a considerable good thermoelectric performance. Among those, cobaltites such as $\mathrm{NaCo}_{2} \mathrm{O}_{4}[38,39]$ or $\mathrm{Ca}_{3} \mathrm{Co}_{4} \mathrm{O}_{9}[40-48]$ were seen as potential $p$-type material in thermoelectric generators. However, they are not stable against temperature cycling and require complex synthesis routes. Concerning $n$-type thermoelectrics, especially titanates such as $\mathrm{SrTiO}_{3}$, show the most promising thermoelectric properties. While their mobility is comparatively low, the effective mass is notably high [49-52], resulting in a very good thermoelectric efficiency. Further improvement was possible by using natural superlattices of $\mathrm{SrTiO}_{3}$, the so-called Ruddlesden-Popper phases [53-55]. Current research also focuses on layered $\operatorname{In}_{2} \mathrm{O}_{3}$ composites, enabling sustainable, cost-effective, and efficient $n$-type thermoelectrics for thermoelectric generators. Korotenchok et al. provide a highly topical review on oxide thermoelectrics with focus on the above-mentioned $\mathrm{In}_{2} \mathrm{O}_{3}$ [56].

Recently, some studies describe copper-iron oxides and claim them as promising thermoelectric materials due to their high Seebeck coefficient, while sustaining a high electrical conductivity and thermal stability [57-60]. Former studies have focused on the thermoelectric performance and the electrical conductivity of the delafossite-type oxide $\mathrm{CuFeO}_{2}$, its dependence on the oxygen partial pressure at high temperatures, and on the novel aerosol deposition coating technique [61-64]. In this work, we focus on the phase stability of delafossites at elevated temperatures and under varying oxygen concentrations. Whereas Stöcker et al. showed an in-situ phase transition by measuring the thermopower of $\mathrm{CuFeO}_{2}$ with increasing oxygen partial pressure, this study aims on a holistic material characterization of $\mathrm{CuFeO}_{2}$ and its stability for their application in thermoelectric generators at high temperatures.

\section{Materials and Methods}

Delafossite powders were prepared in a conventional mixed-oxide technique. In order to obtain a high purity starting material, a synthesis route as reported in [64] was chosen, describing the formation of $\mathrm{CuFeO}_{2}$ with no impurities or secondary phases. As starting materials, copper(I) oxide $(99.9 \%$, Alfa-Aesar, Karlsruhe, Germany) and iron(III) oxide (99\%, Alfa-Aesar, Karlsruhe, Germany) were used and processed in a wet planetary ball mill (Fritsch, Idar-Oberstein, Germany) with cyclohexane as solvent. The stoichiometric mixtures were ball-milled for $4 \mathrm{~h}$ in order to homogenize the materials. After removing the solvent in a rotary evaporator (Heidolph Instruments, Schwabach, Germany), the powders were calcined in a high-temperature furnace (STF/15 450, Carbolite-Gero, Germany) at $1050{ }^{\circ} \mathrm{C}$ for $12 \mathrm{~h}$ in a mixed gas atmosphere of $0 \% \mathrm{O}_{2}, 1 \% \mathrm{O}_{2}$, and $10 \% \mathrm{O}_{2}$ in nitrogen. The obtained delafossite powders were again reground in a planetary mill, sieved with a $90 \mu \mathrm{m}$ screen in order to reduce agglomerates, and dried in a furnace at $200{ }^{\circ} \mathrm{C}$. The phase composition of the obtained powders was elucidated by using an X-ray diffraction system (PANalytical, Almelo, The Netherlands) operating with $\mathrm{CuK}_{\alpha}$ radiation $(1.541874 \AA$ A $)$ within $2 \theta=25^{\circ} \ldots 60^{\circ}$ at a step size of $0.02^{\circ}$.

In order to evaluate the phase composition of $\mathrm{CuFeO}_{2}$ as a function of $p \mathrm{O}_{2}$ at elevated temperatures, $\mathrm{CuFeO}_{2}$ brick shaped pellets were cold-pressed uniaxially [64] and annealed at $900{ }^{\circ} \mathrm{C}$ under different oxygen concentrations $(0,1,5,10,20$, and 100\%) mixed in nitrogen for $12 \mathrm{~h}$. While the oxygen diffusivity of $\mathrm{CuFeO}_{2}$ is low, previous investigations have shown that an annealing time of $12 \mathrm{~h}$ is sufficient for the samples to reach an equilibrium [64]. A scanning electron microscope (LEO 1450 VP, Zeiss, Oberkochen, Germany) was used for energy dispersive X-ray spectroscopy (EDX) and back-scattered electron (BSE) imaging of the samples. Additionally, pellets were reground for X-ray diffraction analysis. This combination of XRD and EDX/BSE studies facilitates an in-depth analysis of the $p \mathrm{O}_{2}$ influence on the crystal structure and phase composition of $\mathrm{CuFeO}_{2}$. Additionally, the results were combined with theoretical calculations of the predominance diagram for the copper-iron-oxygen system in order to verify the experimental findings. 
Since delafossites are possible candidates for high-temperature thermoelectrics, hot-stage XRD (D8 ADVANCE, Bruker with hot stage HTK 1200-N, Anton Paar, $\mathrm{CuK}_{\alpha}$ radiation) analysis of $\mathrm{CuFeO}_{2}$ powder calcined at $1 \% \mathrm{O}_{2}$ in nitrogen was conducted from 20 to $900{ }^{\circ} \mathrm{C}$ under nitrogen gas atmosphere. After an equilibration time of $30 \mathrm{~min}$, XRD patterns were recorded at discrete temperature levels, so possible phase changes could be investigated in operando. Finally, long-term tests of $\mathrm{CuFeO}_{2}$ were performed, by thermally treating bulk samples that were free from secondary phases for $96 \mathrm{~h}$ in nitrogen. These specimens were investigated by a combination of XRD and SEM analysis.

\section{Results and Discussion}

Figure 1 shows the XRD patterns of the calcined delafossite powders and the reference spectrum of delafossite $\mathrm{CuFeO}_{2}$ (JCPDS 39-0246) and indicates no impurities i.e., no secondary phases for samples processed with $1 \% \mathrm{O}_{2}$ mixed in nitrogen. This result is in good agreement with previous investigations [64-67], whereas the calcination in pure $\mathrm{N}_{2}$ leads to an elemental copper phase, due to the reduced oxygen partial pressure. Here, we focus on the influence of an elevated oxygen partial pressure on the phase stability of delafossites. In contrast to characteristic diffraction reflexes of delafossite, $\mathrm{CuFe}_{2} \mathrm{O}_{4}$, and possibly $\mathrm{CuO}$ (marked as + ) are predominant for samples annealed under $10 \%$ oxygen mixed with nitrogen.

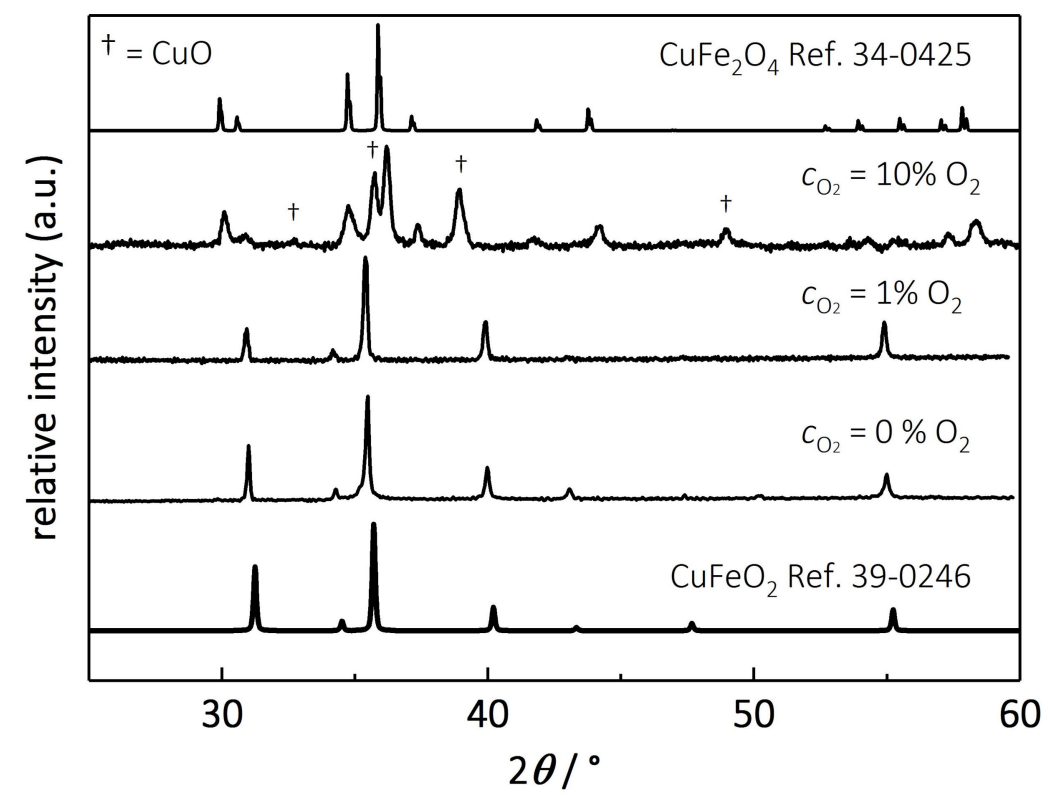

Figure 1. $\mathrm{XRD}$ patterns of $\mathrm{CuFeO}_{2}$ calcined under nitrogen as well as $1 \%$ and $10 \%$ oxygen mixed in nitrogen. Additionally, the reference spectra of $\mathrm{CuFeO}_{2}$ (JCPDS 39-0246) and $\mathrm{CuFe}_{2} \mathrm{O}_{4}$ (JCPDS 34-0425) are depicted.

In order to verify the phase transition of $\mathrm{CuFeO}_{2}$ to $\mathrm{CuFe}_{2} \mathrm{O}_{4}$ and $\mathrm{CuO}$, energy dispersive $\mathrm{X}$-ray spectroscopy investigations were conducted on samples of $\mathrm{CuFeO}_{2}$ calcined in $1 \%$ oxygen and annealed in different oxygen atmospheres. The EDX mapping of characteristic regions of a polished cross-sectional sample, annealed at $900{ }^{\circ} \mathrm{C}$ for $12 \mathrm{~h}$ in a gas mixture of $10 \%$ oxygen in nitrogen, is depicted in Figure 2. It indicates copper, iron, and oxygen. In the element distribution images, two homogeneous distributed phases can be seen, whereas the brightness in the images represents qualitatively the concentration of the corresponding element.

The first phase exhibits no iron and is depicted in Figure $2 \mathrm{a}$ as white zones, consisting of copper and oxygen. Contrarily, the second phase solely contains iron and oxygen, illustrated in Figure $2 b, c$. In order to elucidate the phase composition, quantitative EDX analyses for the cuprous phase (marked as $A$ in Figure 2a) and the ferrous phase (marked as B in Figure $2 b, c$ ) were conducted. The element mole fraction for the two regions and the theoretical compositions of $\mathrm{CuO}$ and $\mathrm{CuFe}_{2} \mathrm{O}_{4}$ are listed in 
Table 1. While the deviation of oxygen in EDX spectroscopy can be up to $3 \mathrm{~mol} \%$, the results provide a rough estimation of the phase compositions.

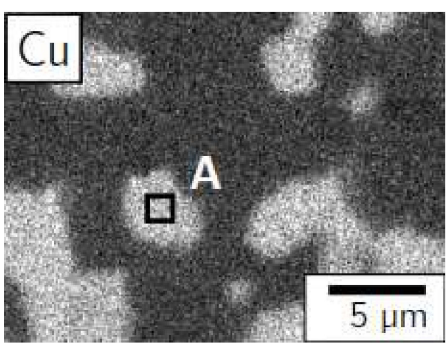

(a)

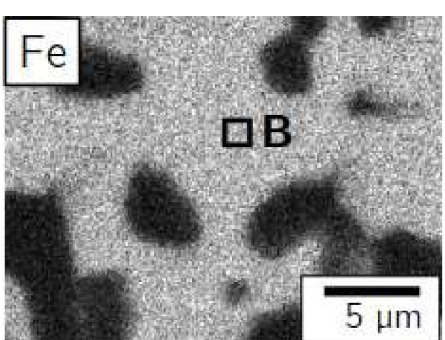

(b)

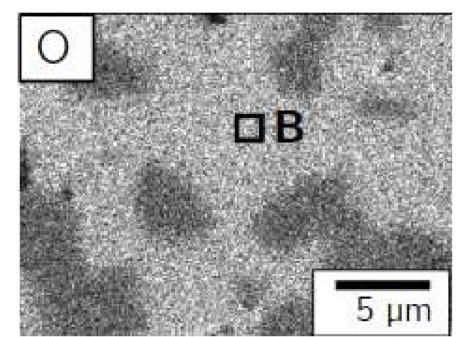

(c)

Figure 2. EDX pattern of the delafossite, annealed at $900{ }^{\circ} \mathrm{C}$ for $12 \mathrm{~h}$ in a gas mixture of $10 \%$ oxygen in nitrogen. (a) copper; (b) iron; (c) oxygen.

Table 1. Calculated element mole fraction based on the quantitative EDX analysis of the two regions marked in Figure 2 and the theoretical composition of $\mathrm{CuO}$ and $\mathrm{CuFe}_{2} \mathrm{O}_{4}$.

\begin{tabular}{ccccc}
\hline Element & Region A & Region B & $\mathbf{C u O}$ & $\mathbf{C u F e}_{\mathbf{2}} \mathbf{O}_{4}$ \\
\hline Copper & $49 \mathrm{~mol} \%$ & $15 \mathrm{~mol} \%$ & $50 \mathrm{~mol} \%$ & $14 \mathrm{~mol} \%$ \\
Iron & - & $24 \mathrm{~mol} \%$ & - & $29 \mathrm{~mol} \%$ \\
Oxygen & $51 \mathrm{~mol} \%$ & $61 \mathrm{~mol} \%$ & $50 \mathrm{~mol} \%$ & $57 \mathrm{~mol} \%$ \\
\hline
\end{tabular}

The findings of the EDX analysis are in line with the results of the XRD recordings. The delafossite is subject to a $p \mathrm{O}_{2}$-dependent phase transition at elevated temperatures to $\mathrm{CuO}$ and $\mathrm{CuFe}_{2} \mathrm{O}_{4}$. Our findings reveal a fully completed conversion when annealing $\mathrm{CuFeO}_{2}$ in a gas mixture of $10 \%$ oxygen in nitrogen. Against the background of thermoelectric performance of delafossites in thermoelectric generators, this phase change limits the usage of $\mathrm{CuFeO}_{2}$ in oxygen-rich atmospheres. While the conduction mechanism of the delafossites is $p$-type, the arising mixed phase of $\mathrm{CuO} / \mathrm{CuFe}{ }_{2} \mathrm{O}_{4}$ shows a mixed conduction, since copper (I) oxide is an $n$-type and the cuprospinel $\mathrm{CuFe}_{2} \mathrm{O}_{4}$ is a $p$-type semiconductor, resulting in bipolar thermoelectric effects and therefore reducing the overall thermoelectric performance $[68,69]$. Previous defect-chemical studies with variations in the oxygen partial pressure on thin delafossite films prepared by aerosol deposition also showed an abrupt change in the conductivity at characteristic $p \mathrm{O}_{2}$ levels at high temperatures, and this change results in bipolar thermoelectric effects [64]. These findings are supported by the results in the present work. They provide a process window for the usage of $\mathrm{CuFeO}_{2}$ as a thermoelectric material at elevated temperatures.

To specify the phase stability threshold for delafossites, $\mathrm{XRD}$ patterns of $\mathrm{CuFeO}_{2}$ samples annealed at $900{ }^{\circ} \mathrm{C}$ in graduated oxygen-nitrogen gas atmospheres were taken. Figure 3 shows the resulting diffraction patterns and the reference spectra of $\mathrm{CuFeO}_{2}$ (JCPDS 39-0246) and $\mathrm{CuFe}_{2} \mathrm{O}_{4}$ (JCPDS 34-0425). 


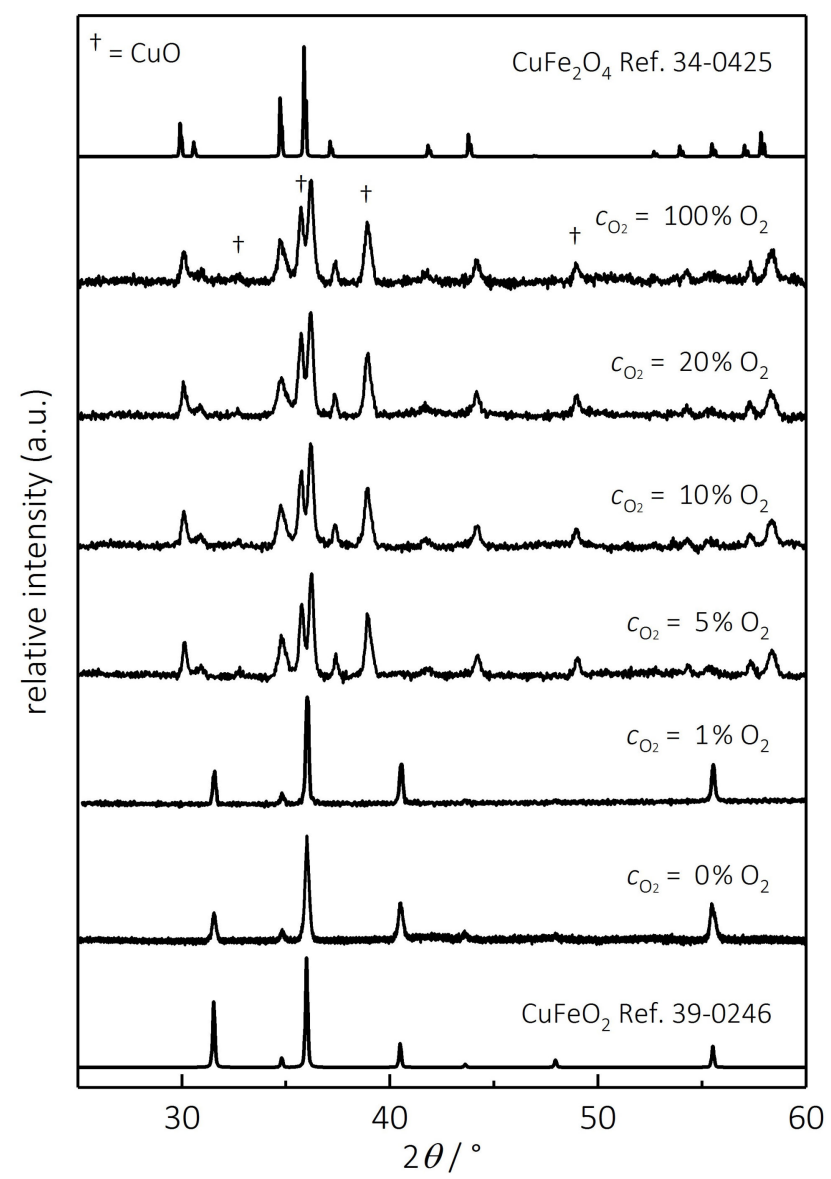

Figure 3. $\mathrm{XRD}$ patterns of $\mathrm{CuFeO}_{2}$ annealed in $900{ }^{\circ} \mathrm{C}$ for $12 \mathrm{~h}$ under different oxygen-nitrogen gas mixtures. Additionally, the reference spectra of $\mathrm{CuFeO}_{2}(\mathrm{JCPDS}=39-0246)$ and $\mathrm{CuFe}_{2} \mathrm{O}_{4}(\mathrm{JCPDS}=34-0425)$ are displayed.

Delafossits annealed in $0 \%$ and $1 \%$ oxygen exhibit no secondary phases, while all samples starting from an oxygen concentration of $5 \%$ show a phase transition to $\mathrm{CuFe}_{2} \mathrm{O}_{4}$ and $\mathrm{CuO}$, with no additional phase changes at higher oxygen partial pressures and no remaining $\mathrm{CuFeO}_{2}$. These findings correspond well with defect-chemical characterizations of $\mathrm{CuFeO}_{2}$, where the phase transition at $900{ }^{\circ} \mathrm{C}$ was observed at oxygen concentrations between 1 and 3.1\% [64]. Hence, these results provide a rough process window in the context of oxygen stability for delafossites at $900{ }^{\circ} \mathrm{C}$. In order to refine these experimental findings, calculations of the equilibrium equation for the oxidization of $\mathrm{CuFeO}_{2}$ according to Equation (1) lead to a theoretical stability window for delafossites.

$$
4 \mathrm{CuFeO}_{2}+\mathrm{O}_{2} \leftrightarrow 2 \mathrm{CuFe}_{2} \mathrm{O}_{4}+2 \mathrm{CuO} .
$$

Equation (1) describes the observed phase transition under oxidizing atmospheres. The Gibbs energy $\Delta G$ of a system is determined by the following expression [70]:

$$
\Delta G=\Delta G^{0}+R T \ln \left(K_{\mathrm{eq}}\right)
$$

$\Delta G^{0}$ stands for the Gibbs free energy change per mole of reaction for unmixed reactants and products at standard conditions, $R$ for the gas constant, $T$ for the absolute temperature, and $K_{\text {eq }}$ denotes the equilibrium constant. If the system is in chemical equilibrium, the Gibbs free energy of Reaction (1) can be calculated as follows, assuming solid solutions for the reactants [71]:

$$
\Delta G^{0}=-R T \ln \left(p \mathrm{O}_{2}\right) .
$$


The Gibbs free energy per mole of formation, $\Delta G^{0,1}$ for Reaction (1), can be described as [71]

$$
\Delta G^{0,1}=-22115 \mathrm{~J} \mathrm{~mol}^{-1}+160.20 \mathrm{~J} \mathrm{~mol}^{-1} K^{-1} \cdot T .
$$

Combined with Expression (3), this yields the Ellingham diagram for Reaction (1) shown in Figure 4.

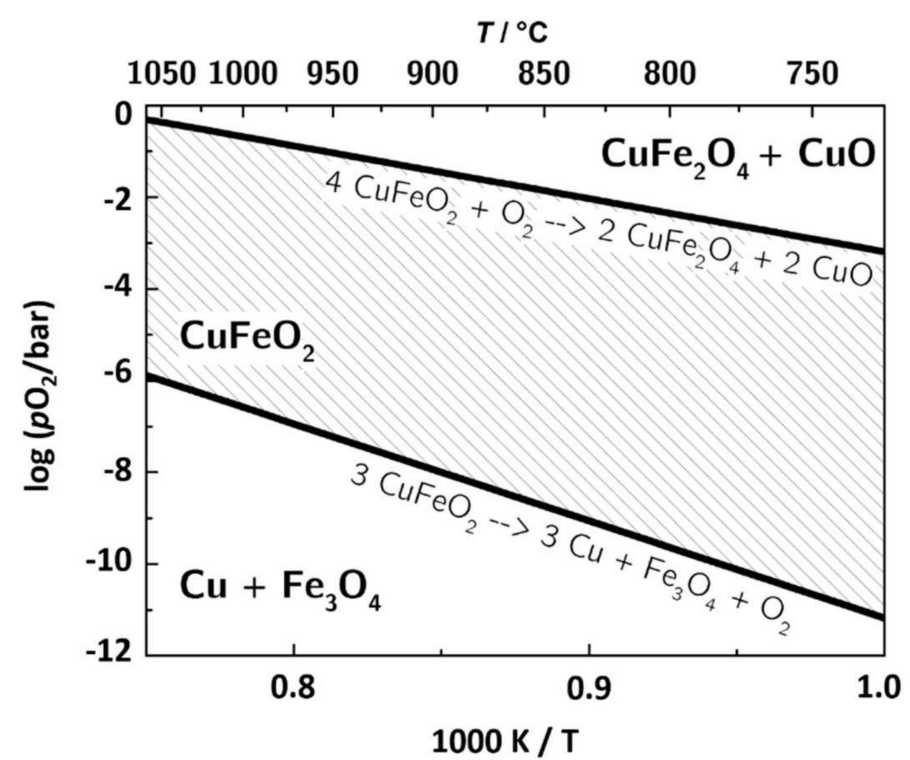

Figure 4. Ellingham diagram of the $\mathrm{CuFeO}_{2}, \mathrm{CuFe}_{2} \mathrm{O}_{4}, \mathrm{CuO}$, and the $\mathrm{Fe}_{3} \mathrm{O}_{4}$ system, respectively.

In addition to the oxidation reaction, the equilibrium curve for the reduction of $\mathrm{CuFeO}_{2}$ at low $p \mathrm{O}_{2}$ corresponding to Expressions (5) and (6) is displayed [71]. The expressions are as follows:

$$
\begin{gathered}
3 \mathrm{CuFeO}_{2} \leftrightarrow 3 \mathrm{Cu}+\mathrm{Fe}_{3} \mathrm{O}_{4}+\mathrm{O}_{2} \\
\Delta G^{0,2}=-405350 \mathrm{~J} \mathrm{~mol}^{-1}+191.40 \mathrm{~J} \mathrm{~mol}^{-1} \mathrm{~K}^{-1} \cdot T .
\end{gathered}
$$

The calculated Ellingham diagram is in good agreement with the experimental findings in this work, verifying the observed phase transitions by XRD and EDX with theoretical calculations. It also supports the thermoelectric measurements in the previous publications [64,72]. For 700, 800, and $900^{\circ} \mathrm{C}$, Table 2 lists upper and lower limit of $\mathrm{pO}_{2}$ for the stability of $\mathrm{CuFeO}_{2}$. At higher oxygen concentrations, the delafossite oxidizes to $\mathrm{CuFe}_{2} \mathrm{O}_{4}$ and $\mathrm{CuO}$ and at low $p \mathrm{O}_{2}$, it decomposes to $\mathrm{Cu}, \mathrm{Fe}_{3} \mathrm{O}_{4}$, and $\mathrm{O}_{2}$. While the reduction of $\mathrm{CuFeO}_{2}$ can be observed during the synthesis at $1050{ }^{\circ} \mathrm{C}$ under nitrogen [64], the employed nitrogen $\left(\mathrm{N}_{2}, 5.0\right)$ contains up to 3 ppm oxygen $\left(p \mathrm{O}_{2}=3 \times 10^{-6}\right.$ bar), resulting in no decomposition at $900{ }^{\circ} \mathrm{C}$.

Table 2. Stability limit of $\mathrm{CuFeO}_{2}$ for three characteristic temperatures, corresponding to the Ellingham diagram shown in Figure 4. The upper (oxidization) and lower (reduction) limits are listed.

\begin{tabular}{cccc}
\hline Temperature & $\mathbf{7 0 0}{ }^{\circ} \mathbf{C}$ & $\mathbf{8 0 0}{ }^{\circ} \mathbf{C}$ & $\mathbf{9 0 0}{ }^{\circ} \mathbf{C}$ \\
\hline Oxidation $/ \log \left(p \mathrm{O}_{2} /\right.$ bar $)$ & -3.50 & -2.40 & -1.48 \\
Reduction $/ \log \left(p \mathrm{O}_{2} /\right.$ bar $)$ & -11.76 & -9.74 & -6.00 \\
\hline
\end{tabular}

These results yield a stability region for the delafossite, depicted as a hatched area in Figure 4, as a function of temperature and oxygen partial pressure. For example, at temperatures above $700{ }^{\circ} \mathrm{C}$, $\mathrm{CuFeO}_{2}$ is not stable in ambient air, so an encapsulation would be required if delafossites are used as thermoelectric materials in high-temperature thermoelectric generators. 
In order to verify the long-term stability of $\mathrm{CuFeO}_{2}$ and to rule out occurring secondary phases when heating up the material, high-temperature XRD was conducted on delafossites in a nitrogen gas atmosphere. Figure 5 depicts the diffraction pattern at different temperatures. Owing to grain growth, the reflexes, respectively the FWHM, broaden with increasing temperature, but no impurities or secondary phases can be detected, confirming that no phase transformations occur from room temperature to $900{ }^{\circ} \mathrm{C}$.

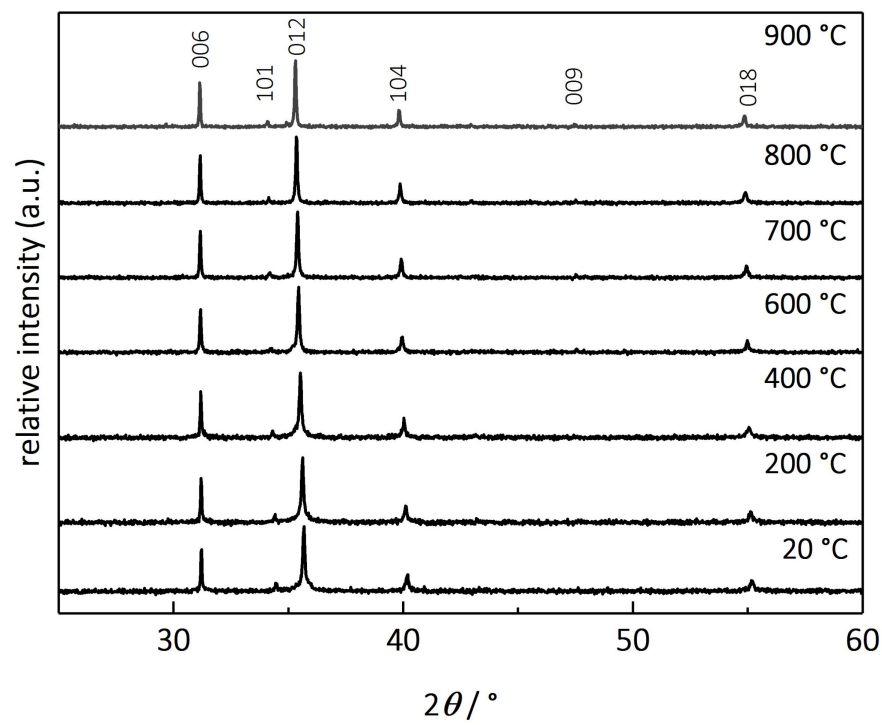

Figure 5. High-temperature $\mathrm{X}$-ray diffraction patterns of $\mathrm{CuFeO}_{2}$, measured in nitrogen at discrete temperature levels as indicated.

The previous investigations were conducted on samples that were annealed for $12 \mathrm{~h}$ in the corresponding gas atmospheres. Especially at high temperatures, aging effects and the interdependency of the substrate with the delafossites, caused by ion exchanges [73,74], may deteriorate the material leading to poorer thermoelectric properties. For this reason, long-term tests of $\mathrm{CuFeO}_{2}$ with no secondary phases on alumina substrates were performed. Figure 6a shows the diffraction pattern of a delafossite annealed in nitrogen at $900{ }^{\circ} \mathrm{C}$ for $96 \mathrm{~h}$, revealing neither impurities nor any phase changes. This result is confirmed by the BSE image in Figure $6 \mathrm{~b}$, where solely $\mathrm{CuFeO}_{2}$ was observed. Neither elemental copper, nor copper-alumina-spinel phases, resulting from possible interactions between the delafossite and the alumina substrate, were detected. The black areas are voids resulting from sample preparation.

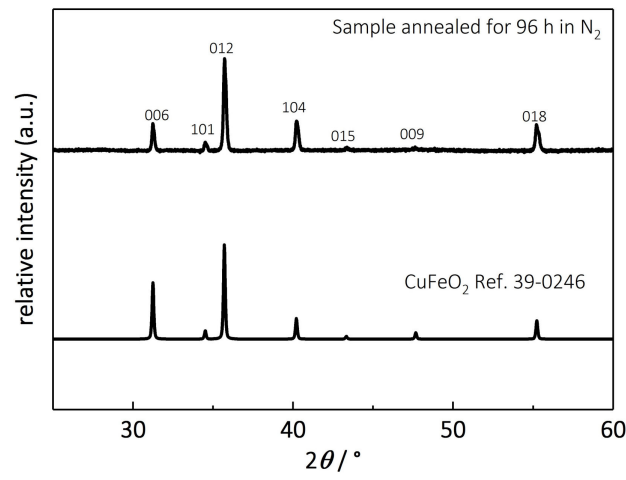

(a)

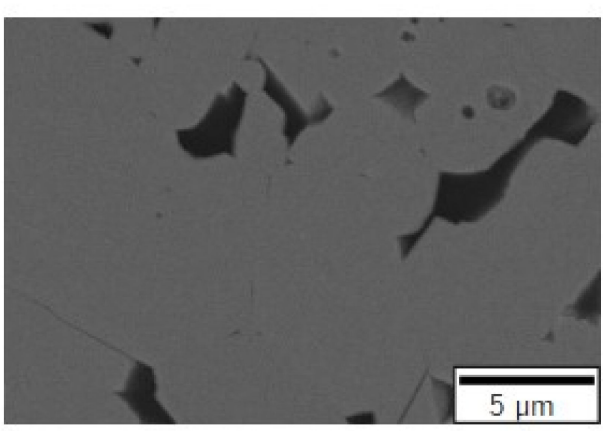

(b)

Figure 6. Delafossite annealed for $96 \mathrm{~h}$ at $900{ }^{\circ} \mathrm{C}$ in nitrogen. (a) Diffraction and reference patterns of $\mathrm{CuFeO}_{2}$ for comparison; (b) scanning microscope image (BSE detector) of the annealed sample showing no secondary phases. The dark areas are voids resulting from sample preparation. 


\section{Conclusions}

In the present study, the phase stability of delafossites at high temperatures and elevated oxygen concentrations was studied. Previous investigations indicated a change in the conduction mechanism of $\mathrm{CuFeO}_{2}$ at high oxygen concentrations, assuming a phase change of the material and reducing the thermoelectric performance. In this work, classical material characterization methods were employed to elucidate this effect in detail. The experimentally obtained results indicated the proposed transition of $\mathrm{CuFeO}_{2}$ to $\mathrm{CuFe}_{2} \mathrm{O}_{4}$ and $\mathrm{CuO}$ being caused by a further oxidation of the delafossites with increasing oxygen partial pressure. Both XRD and SEM/EDX analysis confirmed this reaction, thus limiting the usage of $\mathrm{CuFeO}_{2}$ as high-temperature thermoelectric material to a small process window with respect to oxygen concentration of the ambience and temperature.

While the experimental data gave a rough estimation of the boundaries of the stability of delafossites, theoretical calculations of the Ellingham diagram for the $\mathrm{CuFeO}_{2}$, the $\mathrm{CuFe}_{2} \mathrm{O}_{4}$, and the $\mathrm{CuO}$ system, respectively, lead to a detailed $p \mathrm{O}_{2}$ range in which the delafossites can be considered phase-stable. At temperatures above $700{ }^{\circ} \mathrm{C}$, the upper $p \mathrm{O}_{2}$ limit for the phase change is lower than the oxygen partial pressure of ambient air. Hence, the usage of delafossites as thermoelectric material at high temperatures is limited to low oxygen environments or requires the thermoelectric generator to be encapsulated.

Further investigations and thermoelectric characterizations on the occurring $\mathrm{CuFe}_{2} \mathrm{O}_{4} / \mathrm{CuO}$ bipolar phase may lead to an eligible $n$-type counterpart for delafossites in thermoelectric generators, since both thermoelectric materials could be processed from the same raw material. For that matter, both thermoelectric legs of a thermoelectric generator can be assembled from $\mathrm{CuFeO}_{2}$ as starting material. While the $p$-type legs are protected from an oxidizing gas atmosphere, thus remaining delafossites, the $n$-type legs undergo a phase transition as described in this work, leading to a thermoelectric generator of $p$-type $\mathrm{CuFeO}_{2}$ and $n$-type $\mathrm{CuFe}_{2} \mathrm{O}_{4} / \mathrm{CuO}$.

Author Contributions: R.M. and T.S. planned the experiments. R.M. supervised the study. T.S. conducted the experiments and evaluated the data. All authors contributed to the article.

Funding: This publication was funded by the University of Bayreuth in the funding program-"Open-Access Publishing".

Acknowledgments: The authors are indebted to the following persons and organizations for supporting this work: A. Mergner (Department for Functional Materials) and M. Heider (BIMF) for SEM sample preparation and characterization. W. Milius (Chair of Inorganic Chemistry I) for XRD and U. Glatzel (Metals and Alloys) for high-temperature XRD characterization.

Conflicts of Interest: The authors declare no conflict of interest.

\section{References}

1. Rowe, D.M. CRC Handbook of Thermoelectrics; CRC Press: Boca Raton, FL, USA, 1995.

2. Snyder, G.J.; Toberer, E.S. Complex thermoelectric materials. Nat. Mater. 2008, 7, 105-114. [CrossRef] [PubMed]

3. Nolas, G.S.; Sharp, J.; Goldsmid, H.J. Thermoelectrics: Basic Principles and New Materials Developments; Springer: Berlin, Germany, 2001.

4. Sootsman, J.R.; Chung, D.Y.; Kanatzidis, M.G. Alte und neue Konzepte für thermoelektrische Materialien. Angew. Chem. 2009, 121, 8768-8792. [CrossRef]

5. Rowe, D.M. Thermoelectrics and Its Energy Harvesting: Materials Preparation and Characterization in Thermoelectrics; CRC Press: Boca Raton, FL, USA, 2012.

6. Hong, M.; Chen, Z.-G.; Zou, J. Fundamental and progress of $\mathrm{Bi}_{2} \mathrm{Te}_{3}$-based thermoelectric materials. Chin. Phys. B 2018, 27, 48403. [CrossRef]

7. Zhu, T.; Liu, Y.; Fu, C.; Heremans, J.P.; Snyder, J.G.; Zhao, X. Compromise and Synergy in High-Efficiency Thermoelectric Materials. Adv. Mater. 2017, 29, 1605884. [CrossRef] [PubMed]

8. Ren, G.-K.; Lan, J.-L.; Ventura, K.J.; Tan, X.; Lin, Y.-H.; Nan, C.-W. Contribution of point defects and nano-grains to thermal transport behaviours of oxide-based thermoelectrics. Npj Comput. Mater. 2016, 2, 16023. [CrossRef] 
9. Yin, Y.; Tudu, B.; Tiwari, A. Recent advances in oxide thermoelectric materials and modules. Vacuum 2017, 146, 356-374. [CrossRef]

10. Tomeš, P.; Robert, R.; Trottmann, M.; Bocher, L.; Aguirre, M.H.; Bitschi, A.; Hejtmánek, J.; Weidenkaff, A. Synthesis and characterization of new ceramic thermoelectrics implemented in a thermoelectric oxide module. J. Electron. Mater. 2010, 39, 1696-1703. [CrossRef]

11. Weidenkaff, A.; Robert, R.; Aguirre, M.; Bocher, L.; Lippert, T.; Canulescu, S. Development of thermoelectric oxides for renewable energy conversion technologies. Renew. Energy 2008, 33, 342-347. [CrossRef]

12. Bocher, L.; Aguirre, M.H.; Logvinovich, D.; Shkabko, A.; Robert, R.; Trottmann, M.; Weidenkaff, A. $\left.\left.\mathrm{CaMn}_{(1-\mathrm{x}}\right) \mathrm{Nb}_{(\mathrm{x}}\right)_{3}(\mathrm{x}<0.08)$ perovskite-type phases as promising new high-temperature $n$-type thermoelectric materials. Inorg. Chem. 2008, 47, 8077-8085. [PubMed]

13. Koumoto, K.; Terasaki, I.; Funahashi, R. Complex oxide materials for potential thermoelectric applications. MRS Bull. 2006, 31, 206-210. [CrossRef]

14. Koumoto, K.; Koduka, H.; Seo, W.-S. Thermoelectric properties of single crystal $\mathrm{CuAlO}_{2}$ with a layered structure. J. Mater. Chem. 2001, 11, 251-252. [CrossRef]

15. Koumoto, K.; Funahashi, R.; Guilmeau, E.; Miyazaki, Y.; Weidenkaff, A.; Wang, Y.; Wan, C.; Zhou, X.-D. Thermoelectric ceramics for energy harvesting. J. Am. Ceram. Soc. 2013, 96, 1-23. [CrossRef]

16. Liang, X.; Clarke, D.R. Relation between thermolectric properties and phase equilibria in the $\mathrm{ZnO}_{\mathrm{n}} \mathrm{In}_{2} \mathrm{O}_{3}$ binary system. Acta Mater. 2014, 63, 191-201. [CrossRef]

17. Misture, S.; Edwards, D. High-Temperature oxide thermoelectrics. Am. Ceram. Soc. Bull. 2012, 91, 24-27.

18. Fergus, J.W. Oxide materials for high temperature thermoelectric energy conversion. J. Eur. Ceram. Soc. 2012, 32, 525-540. [CrossRef]

19. Zhao, L.-D.; Tan, G.; Hao, S.; He, J.; Pei, Y.; Chi, H.; Wang, H.; Gong, S.; Xu, H.; Dravid, V.P.; et al. Ultrahigh power factor and thermoelectric performance in hole-doped single-crystal SnSe. Science 2016, 351, 141-144. [CrossRef] [PubMed]

20. Chen, Z.; Jian, Z.; Li, W.; Chang, Y.; Ge, B.; Hanus, R.; Yang, J.; Chen, Y.; Huang, M.; Snyder, G.J.; et al. Lattice dislocations enhancing thermoelectric PbTe in addition to band convergence. Adv. Mater. 2017, 29, 1606768. [CrossRef] [PubMed]

21. Li, J.; Zhang, X.; Chen, Z.; Lin, S.; Li, W.; Shen, J.; Witting, I.T.; Faghaninia, A.; Chen, Y.; Jain, A.; et al. Low-symmetry rhombohedral GeTe thermoelectrics. Joule 2018, 2, 976-987. [CrossRef]

22. Hong, M.; Chen, Z.-G.; Yang, L.; Zou, Y.-C.; Dargusch, M.S.; Wang, H.; Zou, J. Realizing zT of 2.3 in $\mathrm{Ge}_{1-\mathrm{x}-\mathrm{y}} \mathrm{Sb}_{\mathrm{x}} \mathrm{In}_{\mathrm{y}} \mathrm{Te}$ via reducing the phase-transition temperature and introducing resonant energy doping. Adv. Mater. 2018, 30, 1705942. [CrossRef] [PubMed]

23. Hong, M.; Chen, Z.-G.; Matsumura, S.; Zou, J. Nano-scale dislocations induced by self-vacancy engineering yielding extraordinary $\mathrm{n}$-type thermoelectric $\mathrm{Pb}_{0.96-\mathrm{y}} \mathrm{In}_{\mathrm{y}} \mathrm{Se}$. Nano Energy 2018, 50, 785-793. [CrossRef]

24. Hong, M.; Chasapis, T.C.; Chen, Z.-G.; Yang, L.; Kanatzidis, M.G.; Snyder, G.J.; Zou, J. n-type Bi ${ }_{2} \mathrm{Te}_{3-\mathrm{x}} \mathrm{Se}_{\mathrm{x}}$ nanoplates with enhanced thermoelectric efficiency driven by wide-frequency phonon scatterings and synergistic carrier scatterings. ACS Nano 2016, 10, 4719-4727. [CrossRef] [PubMed]

25. Tang, X.; Xie, W.; Li, H.; Zhao, W.; Zhang, Q.; Niino, M. Preparation and thermoelectric transport properties of high-performance p-type $\mathrm{Bi}_{2} \mathrm{Te}_{3}$ with layered nanostructure. Appl. Phys. Lett. 2007, 90, 12102. [CrossRef]

26. Venkatasubramanian, R.; Siivola, E.; Colpitts, T.; O'Quinn, B. Thin-film thermoelectric devices with high room-temperature figures of merit. Nature 2001, 413, 597-602. [CrossRef] [PubMed]

27. Goldsmid, H. Bismuth telluride and its alloys as materials for thermoelectric generation. Materials 2014, 7, 2577-2592. [CrossRef] [PubMed]

28. Chen, G.; Dresselhaus, M.S.; Dresselhaus, G.; Fleurial, J.-P.; Caillat, T. Recent developments in thermoelectric materials. Int. Mater. Rev. 2003, 48, 45-66. [CrossRef]

29. Baba, S.; Sato, H.; Huang, L.; Uritani, A.; Funahashi, R.; Akedo, J. Formation and characterization of polyethylene terephthalate-based $\left(\mathrm{Bi}_{0.15} \mathrm{Sb}_{0.85}\right)_{2} \mathrm{Te}_{3}$ thermoelectric modules with $\mathrm{CoSb}_{3}$ adhesion layer by aerosol deposition. J. Alloys Compd. 2014, 589, 56-60. [CrossRef]

30. Nolas, G.S.; Kaeser, M.; Littleton, R.T.; Tritt, T.M. High figure of merit in partially filled ytterbium skutterudite materials. Appl. Phys. Lett. 2000, 77, 1855-1857. [CrossRef]

31. Sales, B.C.; Mandrus, D.; Chakoumakos, B.C.; Keppens, V.; Thompson, J.R. Filled skutterudite antimonides: Electron crystals and phonon glasses. Phys. Rev. B 1997, 56, 15081-15089. [CrossRef] 
32. Tang, X.; Chen, L.; Goto, T.; Hirai, T. Effects of Ce filling fraction and Fe content on the thermoelectric properties of Co-rich $\mathrm{Ce}_{\mathrm{y}} \mathrm{Fe}_{\mathrm{x}} \mathrm{Co}_{4-\mathrm{x}} \mathrm{Sb}_{12}$. J. Mater. Res. 2001, 16, 837-843. [CrossRef]

33. Stöcker, T.; Köhler, A.; Moos, R. Why does the electrical conductivity in PEDOT:PSS decrease with PSS content? A study combining thermoelectric measurements with impedance spectroscopy. J. Polym. Sci. Part B Polym. Phys. 2012, 50, 976-983. [CrossRef]

34. Kim, G.-H.; Shao, L.; Zhang, K.; Pipe, K.P. Engineered doping of organic semiconductors for enhanced thermoelectric efficiency. Nat. Mater. 2013, 12, 719-723. [CrossRef] [PubMed]

35. He, J.; Kanatzidis, M.G.; Dravid, V.P. High performance bulk thermoelectrics via a panoscopic approach. Mater. Today 2013, 16, 166-176. [CrossRef]

36. Plochmann, B.; Lang, S.; Rüger, R.; Moos, R. Optimization of thermoelectric properties of metal-oxide-based polymer composites. J. Appl. Polym. Sci. 2013, 131, 40038. [CrossRef]

37. Bubnova, O.; Crispin, X. Towards polymer-based organic thermoelectric generators. Energy Environ. Sci. 2012, 5, 9345-9362. [CrossRef]

38. Fujita, K.; Mochida, T.; Nakamura, K. High-temperature thermoelectric properties of $\mathrm{Na}_{\mathrm{x}} \mathrm{CoO}_{2}$ single crystals. Jpn. J. Appl. Phys. 2001, 40, 4644-4647. [CrossRef]

39. Tsai, P.H.; Norby, T.; Tan, T.T.; Donelson, R.; Chen, Z.D.; Li, S. Correlation of oxygen vacancy concentration and thermoelectric properties in $\mathrm{Na}_{0,73} \mathrm{CoO}_{2-\delta}$. Appl. Phys. Lett. 2010, 96, 141905. [CrossRef]

40. Paul, B.; Schroeder, J.L.; Kerdsongpanya, S.; van Nong, N.; Schell, N.; Ostach, D.; Lu, J.; Birch, J.; Eklund, P. Mechanism of formation of the thermoelectric layered cobaltate $\mathrm{Ca}_{3} \mathrm{Co}_{4} \mathrm{O}_{9}$ by annealing of $\mathrm{CaO}-\mathrm{CoO}$ thin films. Adv. Electron. Mater. 2015, 1, 1400022. [CrossRef]

41. Paul, B.; Lu, J.; Eklund, P. Nanostructural tailoring to induce flexibility in thermoelectric $\mathrm{Ca}_{3} \mathrm{Co}_{4} \mathrm{O}_{9}$ thin films. ACS Appl. Mater. Interfaces 2017, 9, 25308-25316. [CrossRef] [PubMed]

42. Paul, B.; Björk, E.M.; Kumar, A.; Lu, J.; Eklund, P. Nanoporous $\mathrm{Ca}_{3} \mathrm{Co}_{4} \mathrm{O}_{9}$ thin films for transferable thermoelectrics. ACS Appl. Energy Mater. 2018, 1, 2261-2268. [CrossRef] [PubMed]

43. Saini, S.; Yaddanapudi, H.S.; Tian, K.; Yin, Y.; Magginetti, D.; Tiwari, A. Terbium ion doping in $\mathrm{Ca}_{3} \mathrm{Co}_{4} \mathrm{O}_{9}$ : A step towards high-performance thermoelectric materials. Sci. Rep. 2017, 7, 44621. [CrossRef] [PubMed]

44. Prevel, M.; Reddy, E.S.; Perez, O.; Kobayashi, W.; Terasaki, I.; Goupil, C.; Noudem, J.G. Thermoelectric properties of sintered and textured Nd-substituted $\mathrm{Ca}_{3} \mathrm{Co}_{4} \mathrm{O}_{9}$ ceramics. Jpn. J. Appl. Phys. 2007, 46, 6533-6538. [CrossRef]

45. Mikami, M.; Funahashi, R. The effect of element substitution on high-temperature thermoelectric properties of $\mathrm{Ca}_{3} \mathrm{Co}_{2} \mathrm{O}_{6}$ compounds. J. Solid State Chem. 2005, 178, 1670-1674. [CrossRef]

46. Nong, N.V.; Liu, C.-J.; Ohtaki, M. High-temperature thermoelectric properties of late rare earth-doped $\mathrm{Ca}_{3} \mathrm{Co}_{4} \mathrm{O}_{9+\delta}$. J. Alloys Compd. 2011, 509, 977-981. [CrossRef]

47. Soon-mok, C.; Chang-Hyun, L.I.M.; Won-Seon, S.E.O. High-temperature thermoelectric properties of the $\mathrm{Ca}_{3-\mathrm{x}} \mathrm{K}_{\mathrm{x}} \mathrm{Co}_{4} \mathrm{O}_{9}(0 \leq \mathrm{x} \leq 0.3)$ system. J. Korean Phys. Soc. 2010, 57, 1054-1058.

48. Bresch, S.; Mieller, B.; Selleng, C.; Stöcker, T.; Moos, R.; Rabe, T. Influence of the calcination procedure on the thermoelectric properties of calcium cobaltite $\mathrm{Ca}_{3} \mathrm{Co}_{4} \mathrm{O}_{9}$. J. Electroceram. 2018, 40, 225-234. [CrossRef]

49. Muta, H.; Kurosaki, K.; Yamanaka, S. Thermoelectric properties of reduced and La-doped single-crystalline $\mathrm{SrTiO}_{3}$. J. Alloys Compd. 2005, 392, 306-309. [CrossRef]

50. Ohta, S.; Nomura, T.; Ohta, H.; Hirano, M.; Hosono, H.; Koumoto, K. Large thermoelectric performance of heavily $\mathrm{Nb}$-doped $\mathrm{SrTiO}_{3}$ epitaxial film at high temperature. Appl. Phys. Lett. 2005, 87, 92108. [CrossRef]

51. Moos, R.; Härdtl, K.H. Electronic transport properties of $\mathrm{Sr}_{1-x} \mathrm{La}_{x} \mathrm{TiO}_{3}$ ceramics. J. Appl. Phys. 1996, 80, $393-400$. [CrossRef]

52. Moos, R.; Gnudi, A.; Härdtl, K.H. Thermopower of $\mathrm{Sr}_{1-x} \mathrm{La}_{x} \mathrm{TiO}_{3}$ ceramics. J. Appl. Phys. 1995, 78, $5042-5047$. [CrossRef]

53. Wang, Y.; Lee, K.H.; Ohta, H.; Koumoto, K. Thermoelectric properties of electron doped $\mathrm{SrO}\left(\mathrm{SrTiO}_{3}\right)_{\mathrm{n}}$ (n =1,2) ceramics. J. Appl. Phys. 2009, 105, 103701. [CrossRef]

54. Haeni, J.H.; Theis, C.D.; Schlom, D.G.; Tian, W.; Pan, X.Q.; Chang, H.; Takeuchi, I.; Xiang, X.-D. Epitaxial growth of the first five members of the $\mathrm{Sr}_{n+1} \mathrm{Ti}_{n} \mathrm{O}_{3 n+1}$ Ruddlesden-Popper homologous series. Appl. Phys. Lett. 2001, 78, 3292-3294. [CrossRef]

55. Lee, K.H.; Kim, S.W.; Ohta, H.; Koumoto, K. Ruddlesden-Popper phases as thermoelectric oxides. Nb-doped $\mathrm{SrO}\left(\mathrm{SrTiO}_{3}\right)_{n}(n=1,2)$. J. Appl. Phys. 2006, 100, 63717. [CrossRef] 
56. Korotcenkov, G.; Brinzari, V.; Cho, B.K. $\mathrm{In}_{2} \mathrm{O}_{3}$-based multicomponent metal oxide films and their prospects for thermoelectric applications. Solid State Sci. 2016, 52, 141-148. [CrossRef]

57. Ono, Y.; Satoh, K.-I.; Nozaki, T.; Kajitani, T. Structural, magnetic and thermoelectric properties of delafossite-type oxide, $\mathrm{CuCr}_{1-\mathrm{x}} \mathrm{Mg}_{\mathrm{x}} \mathrm{O}_{2}(0 \leq \mathrm{x} \leq 0.05)$. Jpn. J. Appl. Phys. 2007, 46, 1071-1075. [CrossRef]

58. Nozaki, T.; Hayashi, K.; Kajitani, T. Thermoelectric properties of delafossite-type oxide $\mathrm{CuFe}_{1-\mathrm{x}} \mathrm{Ni}_{\mathrm{x}} \mathrm{O}_{2}$ $(0 \leq \mathrm{x} \leq$ 0.05). J. Chem. Eng. Jpn. 2007, 40, 1205-1209. [CrossRef]

59. Nozaki, T.; Hayashi, K.; Kajitani, T. Electronic structure and thermoelectric properties of the delafossite-type oxides $\mathrm{CuFe}_{1-\mathrm{x}} \mathrm{Ni}_{\mathrm{x}} \mathrm{O}_{2}$. J. Electron. Mater. 2009, 38, 1282-1286. [CrossRef]

60. Hayashi, K.; Nozaki, T.; Kajitani, T. Structure and high temperature thermoelectric properties of delafossite-type oxide $\mathrm{CuFe}_{1-\mathrm{x}} \mathrm{Ni}_{\mathrm{x}} \mathrm{O}_{2}(0 \leq \mathrm{x} \leq 0.05)$. Jpn. J. Appl. Phys. 2007, 46, 5226-5229. [CrossRef]

61. Kim, Y.; Ahn, C.-W.; Choi, J.-J.; Ryu, J.; Kim, J.-W.; Yoon, W.-H.; Park, D.-S.; Yoon, S.-Y.; Ma, B.; Hahn, B.-D. Next generation ceramic substrate fabricated at room temperature. Sci. Rep. 2017, 7, 6637. [CrossRef] [PubMed]

62. Hanft, D.; Exner, J.; Schubert, M.; Stöcker, T.; Fuierer, P.; Moos, R. An overview of the aerosol deposition method: Process fundamentals and new trends in materials applications. J. Ceram. Sci. Technol. 2015, 6, 147-182.

63. Akedo, J. Room temperature impact consolidation (RTIC) of fine ceramic powder by aerosol deposition method and applications to microdevices. J. Therm. Spray Technol. 2008, 17, 181-198. [CrossRef]

64. Stöcker, T.; Exner, J.; Schubert, M.; Streibl, M.; Moos, R. Influence of oxygen partial pressure during processing on the thermoelectric properties of aerosol-deposited $\mathrm{CuFeO}_{2}$. Materials 2016, 9, 227. [CrossRef] [PubMed]

65. Amrute, A.P.; Łodziana, Z.; Mondelli, C.; Krumeich, F.; Pérez-Ramírez, J. Solid-state chemistry of cuprous delafossites: Synthesis and stability aspects. Chem. Mater. 2013, 25, 4423-4435. [CrossRef]

66. Zhao, T.-R.; Hasegawa, M.; Takei, H. Oxygen nonstoichiometry in copper iron oxide $\left[\mathrm{CuFeO}_{2+\delta}\right]$ single crystals. J. Cryst. Growth 1997, 181, 55-60. [CrossRef]

67. Zhao, T.-R.; Hasegawa, M.; Takei, H. Phase equilibrium of the $\mathrm{Cu}-\mathrm{Fe}-\mathrm{O}$ system under $\mathrm{Ar}, \mathrm{CO}_{2}$ and $\mathrm{Ar}+0.5 \%$ $\mathrm{O}_{2}$ atmospheres during $\mathrm{CuFeO}_{2}$ single-crystal growth. J. Mater. Sci. 1996, 31, 5657-5663. [CrossRef]

68. Greenwood, N.N.; Anderson, J.S. Conductivity and thermo-electric effect in cuprous oxide. Nature 1949, 164, 346-347. [CrossRef]

69. Suda, S.; Fujitsu, S.; Koumoto, K.; Yanagida, H. The effect of atmosphere and doping on electrical conductivity of CuO. Jpn. J. Appl. Phys. 1992, 31, 2488-2491. [CrossRef]

70. Ellingham, H.J.T. Transactions and communications. J. Chem. Technol. Biotechnol. 1944, 63, 125-160.

71. Schaefer, S.C.; Hundley, G.L.; Block, F.E.; McCune, R.A.; Mrazek, R.V. Phase equilibria and X-ray diffraction investigation of system Cu-Fe-O. Metall. Trans. 1970, 1, 2557-2563.

72. Hayashi, K.; Sato, K.-I.; Nozaki, T.; Kajitani, T. Effect of doping on thermoelectric properties of delafossite-type oxide $\mathrm{CuCrO}_{2}$. Jpn. J. Appl. Phys. 2008, 47, 59-63. [CrossRef]

73. Barnabé, A.; Mugnier, E.; Presmanes, L.; Tailhades, P. Preparation of delafossite $\mathrm{CuFeO}_{2}$ thin films by rf-sputtering on conventional glass substrate. Mater. Lett. 2006, 60, 3468-3470. [CrossRef]

74. Zhao, T.-R.; Hasegawa, M.; Takei, H. Crystal growth and characterization of cuprous ferrite $\left(\mathrm{CuFeO}_{2}\right)$. J. Cryst. Growth 1996, 166, 408-413. [CrossRef]

(C) 2018 by the authors. Licensee MDPI, Basel, Switzerland. This article is an open access article distributed under the terms and conditions of the Creative Commons Attribution (CC BY) license (http://creativecommons.org/licenses/by/4.0/). 